\title{
Combined percutaneous treatment of atrial septal defect and pulmonic or aortic stenosis in adult patients
}

\author{
Pavol Tomasov, Katerina Linhartova, Petra Antonova, Radka Adlova, David Alan, Josef Veselka
}

Cardiology Department, Cardiovascular Center, University Hospital Motol, Prague, Czech Republic

Submitted: 14 August 2010

Accepted: 20 October 2010

Arch Med Sci 2010; 6, 6: 976-980

DOI: $10.5114 /$ aoms.2010.19312

Copyright @ 2010 Termedia \& Banach

\begin{abstract}
Combined atrial septal defect and pulmonic or aortic stenosis are relatively uncommon conditions in adult patients, with few reported cases of percutaneous treatment. We present two patients with secundum type atrial septal defect and concomitant pulmonic or aortic stenosis and their treatment by transcatheter techniques.
\end{abstract}

Key words: heart septal defects, septal occluder device, balloon valvuloplasty

\section{Introduction}

Secundum type atrial septal defect (ASD) combined with pulmonic or aortic stenosis is a relatively uncommon condition in adult patients. Percutaneous closure of ASD in indicated patients is a legitimate alternative to surgical treatment. Percutaneous balloon valvuloplasty for pulmonic stenosis, described in 1982 [1], is a procedure of choice for both adolescent and adult patients (class I recommendation according to the ACC/AHA guidelines [2]). There are several reports of patients being treated by a percutaneous technique, either staged or combined, with no clear agreement as to which procedure should be performed first [3-4].

Percutaneous balloon valvuloplasty for calcific aortic stenosis might be considered as a palliative treatment for patients eligible for neither a surgical approach nor transcatheter aortic valve implantation (TAVI) [2]. There is a report of a combined percutaneous ASD closure and double balloon valvotomies for mitral and aortic stenosis in a patient with Lutembacher's syndrome [5].

\section{Case report}

\section{Patient 1}

A 63-year-old woman underwent a transthoracic and transoesophageal echocardiogram due to dyspnoea on exertion (NYHA class II). She was diagnosed with a large secundum type atrial septal defect $(19 \mathrm{~mm}$ in diameter, Figure 1) with left-to-right shunt and pulmonic stenosis (maximal pressure gradient $49 \mathrm{mmHg}$ ). The patient was referred for percutaneous closure of the ASD and pulmonic balloon valvuloplasty.

Coronary angiography with normal findings was performed via the right femoral artery. Right heart catheterization was performed via the right

\author{
Corresponding author: \\ Pavol Tomasov, MD \\ Cardiology Department \\ Cardiovascular Center \\ University Hospital Motol \\ $\checkmark$ uvalu 84 \\ Prague, 150 06, Czech Republic \\ Phone: +420 224434901 \\ Fax: +420 224434920 \\ E-mail: p.tomasov@seznam.cz
}


femoral vein. The left-to-right shunt ratio of pulmonary blood flow (Qp) to systemic blood flow (Qs) was assessed to be $1.45: 1$. The peak-to-peak pressure gradient across the pulmonary valve was $35 \mathrm{mmHg}$.

First, the ASD was closed using a $21 \mathrm{~mm}$ Figulla Occluder device (Occlutech GmbH, Jena, Germany) under transoesophageal echocardiographic guidance (Figure 2). The peak-to-peak pressure gradient across the valve was measured again and showed $33 \mathrm{mmHg}$. Therefore, pulmonary balloon valvuloplasty was performed with a NUCLEUS ${ }^{T M} 25 \times 30 \mathrm{~mm}$ percutaneous transluminal valvuloplasty catheter (NuMED, Inc., Hopkinton, NY, Figure 3). The resulting peak-to-peak pressure gradient was $10 \mathrm{mmHg}$.

The patient was started on dual antiplatelet therapy (aspirin $100 \mathrm{mg}$ daily and clopidogrel $75 \mathrm{mg}$ daily for 6 months). Follow-up echocardiogram 2 months after the procedure showed no residual shunt and a maximal pressure gradient across the pulmonary valve of $38 \mathrm{mmHg}$ and the patient reported an improvement in the functional class (NYHA I). Six months after the procedure, the maximal pressure gradient declined to $25 \mathrm{mmHg}$

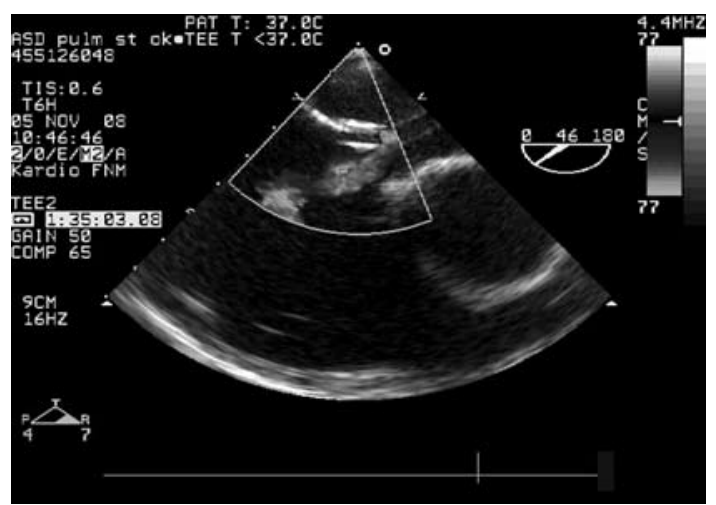

Figure 1. Transoesophageal echocardiogram of a secundum type ASD with a Multipurpose catheter (Cordis, Miami Lakes, FL) crossing the defect from right to left atrium

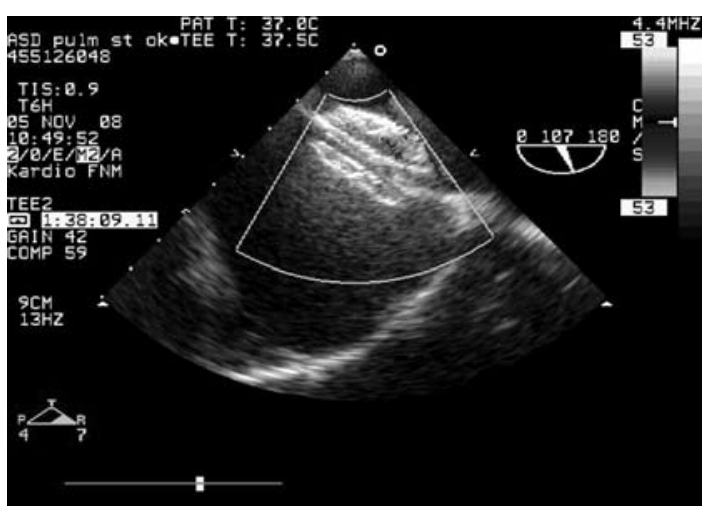

Figure 2. Transoesophageal echocardiogram after ASD closure and a recent one-year follow-up showed a further decline to $16 \mathrm{~mm} \mathrm{Hg}$ as well as a new dilatation of the pulmonary artery to a diameter of $50 \mathrm{~mm}$.

\section{Patient 2}

A 78-year-old woman was admitted to the hospital due to heart failure symptoms (dyspnoea, fatigue, peripheral oedema). Shortly after admission, respiratory distress occurred due to pulmonary oedema and the patient had to be artificially ventilated. Transoesophageal echocardiogram showed a severe calcific aortic stenosis with $102 \mathrm{mmHg}$ maximal and $56 \mathrm{mmHg}$ mean pressure gradient and a large secundum type ASD (17 $\mathrm{mm}$ in diameter) with left-to-right shunt (Figure 4). She was referred for combined percutaneous aortic balloon valvuloplasty and ASD closure.

Right heart catheterization was performed via the right jugular vein. Temporary pacing was introduced into the right ventricle via the right

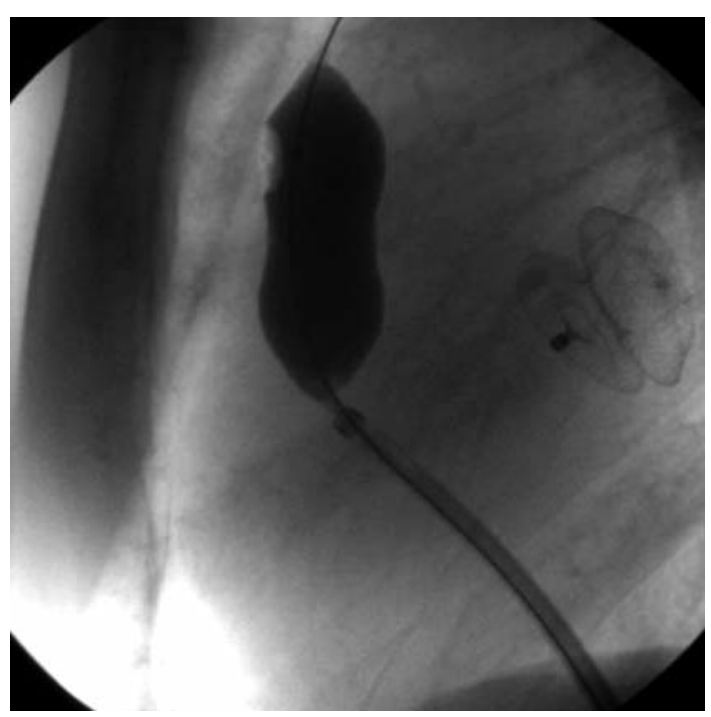

Figure 3. Balloon valvuloplasty of pulmonary valvular stenosis following ASD closure

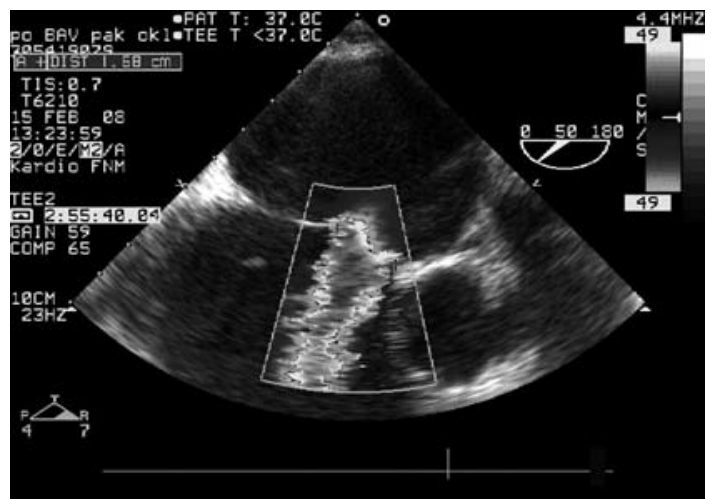

Figure 4. Transoesophageal echocardiogram of a secundum type ASD 
femoral vein. Coronary angiography and left heart catheterization were performed via the right femoral artery. No significant coronary stenosis was found and the left-to-right shunt ratio of Qp to Qs was 1.5 : 1 . Peak-to-peak pressure gradient across the aortic valve was $50 \mathrm{mmHg}$. Aortic balloon valvuloplasty with a NuCLEUSTM $22 \times 40 \mathrm{~mm}$ percutaneous transluminal valvuloplasty catheter (NuMED, Inc., Hopkinton, NY) was accomplished. The resulting peak-to-peak pressure gradient was $10 \mathrm{mmHg}$. Next, under transoesophageal echocardiographic guidance, sizing of the ASD using a $17 \mathrm{~mm}$ balloon while measuring the pulmonary artery (PA) and pulmonary capillary wedge (PCW) pressures was achieved (Figures 5, 6). After ruling out elevation in PA pressures during the sizing balloon inflation, the ASD was successfully closed with an $18 \mathrm{~mm}$ Figulla Occluder device (Occlutech $\mathrm{GmbH}$, Jena, Germany, Figures 7, 8).

The patient was started on a dual antiplatelet therapy (aspirin $100 \mathrm{mg}$ daily and clopidogrel $75 \mathrm{mg}$ daily for 2 months). Shortly after the procedure the heart failure symptoms subsided.

The patient died 18 months later of a sudden cardiac death. The autopsy showed a completely

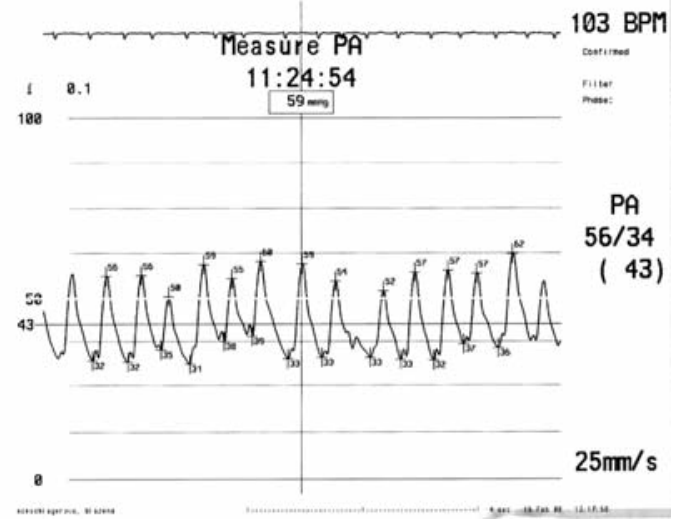

Figure 5. Pulmonary artery pressure measurement before ASD occlusion

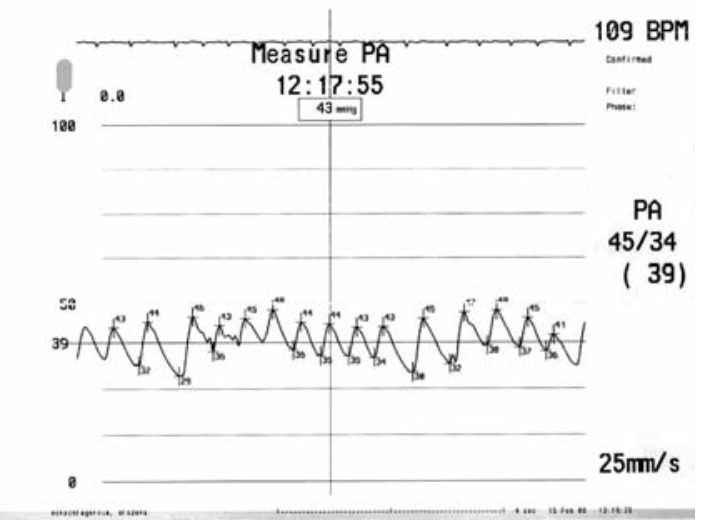

Figure 6. Pulmonary artery pressure measurement immediately after ASD occlusion endothelised Figulla occluder device with no residual shunt (Figures 9, 10).

\section{Discussion}

In adult patients, combined occurrence of secundum type ASD and pulmonic stenosis is an uncommon condition. When isolated, both conditions can be treated percutaneously. Several reports describing a transcatheter approach for the treatment of combined secundum type ASD and pulmonic stenosis vary in answering the question which defect should be treated first and whether the procedures should be staged or combined [3-4].

Treating the ASD first should eliminate the leftto-right shunt and thus also the right ventricle volume overload and possibly lower the pressure gradient across the pulmonic valve, enabling one to reassess the pulmonic stenosis severity. On the other hand, addressing the pulmonic stenosis first lowers the peri-procedural risk of ASD occluder device dislodgement.

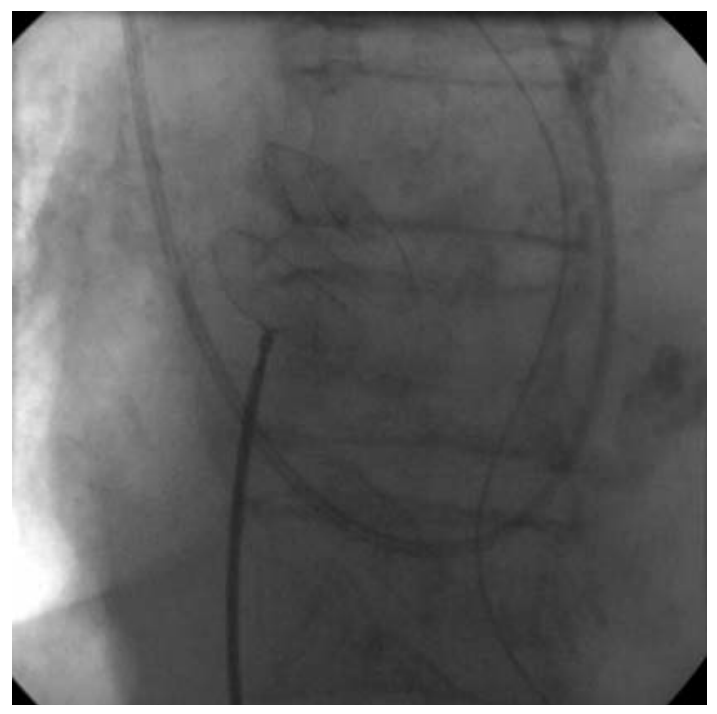

Figure 7. ASD closure

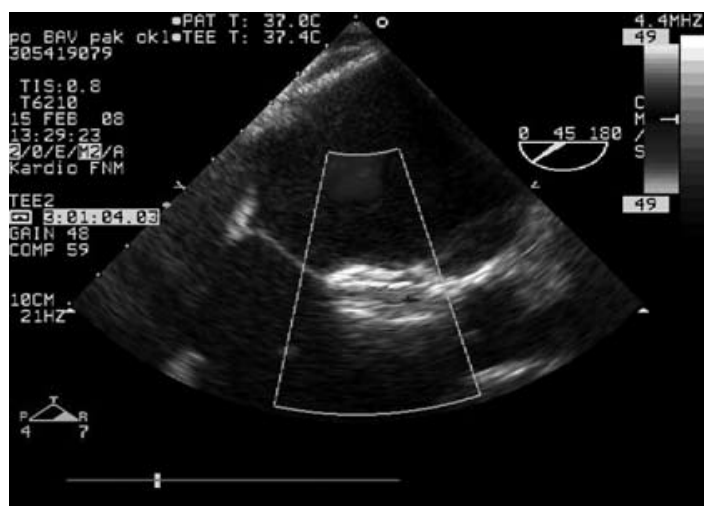

Figure 8. Transoesophageal echocardiogram after ASD closure 


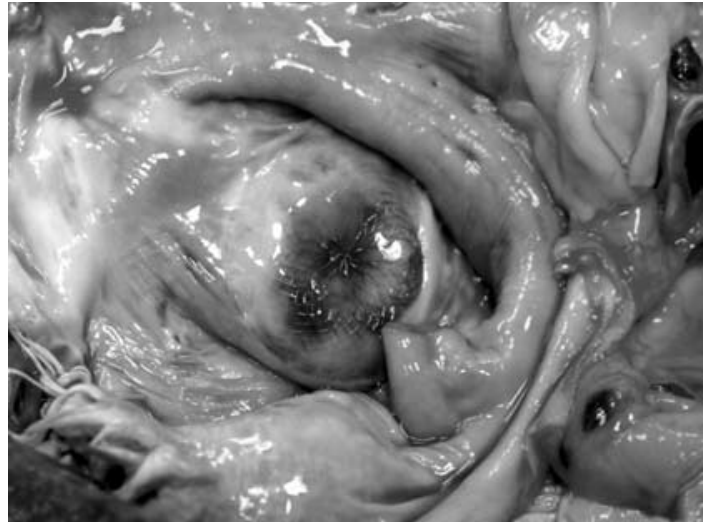

Figure 9. Completely endothelised occluder device viewed from the left atrium with no residual shunt

With the pulmonic valve peak-to-peak pressure gradient being only $5 \mathrm{mmHg}$ above the cut-off value for interventional treatment of pulmonic stenosis in symptomatic patients ( $30 \mathrm{mmHg}$ ), we decided to correct the ASD first. The $Q_{p} / Q_{s}$ ratio $(1.45: 1)$ was slightly below the $1.5: 1$ value. The ASD itself, however, was large (19 $\mathrm{mm}$ in diameter) and we expected the left-to-right shunt ratio to be diminished by the elevated pressures in the rightsided chambers. Treating the ASD first allowed us to reassess the pulmonic stenosis, with the peakto-peak pressure gradient remaining above the $30 \mathrm{mmHg}$ threshold, and thus we decided to proceed with the pulmonic balloon valvuloplasty.

Our patient with pulmonary valvular stenosis and ASD was older than patients in previously published reports. She remained asymptomatic up to the age of 63 years probably due to only borderline Qp/Qs ratio and only mildly elevated pulmonary valve pressure gradient. The late pulmonary artery dilatation in our patient demonstrates a need for a thorough follow-up examination.

The percutaneous treatment of ASD and calcific aortic stenosis has not been previously reported. At present, with TAVI being an alternative form of treatment of patients with calcific aortic stenosis not eligible for surgical valve replacement, aortic balloon valvuloplasty is being used in fewer cases or has been abandoned completely [6]. The reasons for it falling out of favour are mainly a high rate of restenosis and a small haemodynamic effect. However, in everyday clinical practice in the setting of an expanding elderly population there are patients who could benefit from this procedure [7]. We encountered an older, high-risk patient with severe comorbidities and in critical condition, who was eligible for neither surgical treatment, nor TAVI. Therefore, we decided to perform an aortic balloon valvuloplasty as a palliative treatment combined with ASD closure of a large defect with significant

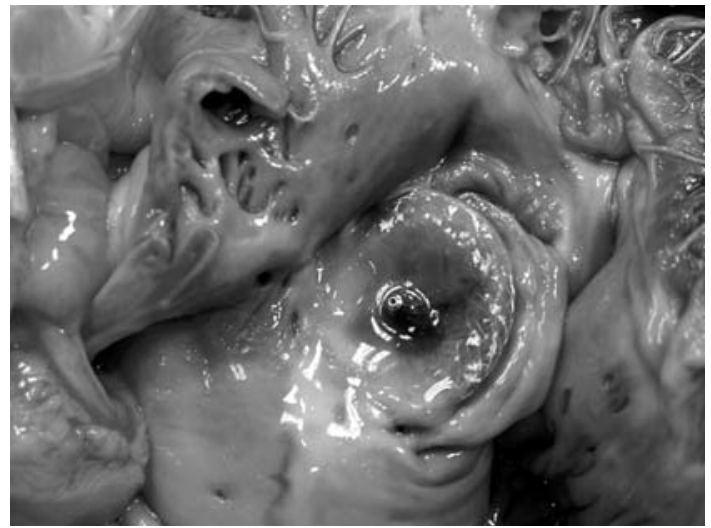

Figure 10. Completely endothelised occluder device viewed from the right atrium

left-to-right shunt. Before the actual occlusion of the ASD we carefully monitored the PA and PCW pressure during balloon occlusion of the defect, in case the elimination of the shunt worsened the situation in the pulmonary bed.

lOur case reports show that secundum type ASD combined with pulmonic or aortic valve stenosis can be treated by a one-stage percutaneous procedure. In the case of ASD and pulmonic stenosis, there is no clear agreement as to which defect should be treated first. Before the ASD closure in a patient with aortic stenosis, a careful haemodynamic assessment is essential.

\section{Acknowledgment}

Supported by the Czech Ministry of Health MZOFNM2005.

\section{References}

1. Kan JS, White RI Jr, Mitchell SE, Gardner TJ. Percutaneous balloon valvuloplasty: A new method for treating congenital pulmonary-valve stenosis. N Engl J Med 1982; 307: 540-2.

2. Bonow RO, Carabello BA, Chatterjee K, et al. ACC/AHA 2006 guidelines for the management of patients with valvular heart disease: A report of the American College of Cardiology/American Heart Association Task Force on Practice Guidelines (writing Committee to Revise the 1998 guidelines for the management of patients with valvular heart disease) developed in collaboration with the Society of Cardiovascular Anesthesiologists endorsed by the Society for Cardiovascular Angiography and Interventions and the Society of Thoracic Surgeons. J Am Coll Cardiol 2006; 48:e1-e148.

3. Wahl A, Windecker S, Misteli M, Meier B. Combined percutaneous pulmonary valvuloplasty and atrial septal defect closure for pulmonary valvular stenosis and associated secundum atrial septal defect in an adult. Catheter Cardiovasc Interv 2001; 53: 68-70.

4. Vera JA, Nounou M, Kern M. Staged Percutaneous Atrial Septal Defect Closure and Pulmonic Balloon Valvuloplasty in an Adult with Congenital Heart Disease. Catheter Cardiovasc Interv 2008; 72: 416-23. 
5. Ruiz CE, Gamra H, Mahrer P, Allen JW, O'Laughlin MP, Lau FYK. Percutaneous closure of a secundum atrial septal defect and double balloon valvotomies of a severe mitral and aortic valve stenosis in a patient with Lutembacher's syndrome and severe pulmonary hypertension. Cathet Cardiovasc Diagn 1991; 25: 309-12.

6. Akin I, Kische S, Rehders TC, et al. Indication for percutaneous aortic valve implantation. Arch Med Sci 2010; 3: 296-302.

7. Hara H, Pedersen WR, Ladich E, et al. Percutaneous balloon aortic valvuloplasty revisited. Time for a renaissance? Circulation 2007; 115: e334-e338. 